\title{
Early HIV-1 Infection Is Associated With Reduced Frequencies of Cervical Th17 Cells
}

\author{
Lyle R. McKinnon, PhD, *† + Billy Nyanga, MSc, * Connie J. Kim, PhD, $†$ Preston Izulla, MBChB, MPH,* \\ Jessie Kwatampora, MBChB, MPH, * Makobu Kimani, MBChB, MPH, ${ }^{*}$ Kamnoosh Shahabi, MSc, $\dagger$ \\ Nelly Mugo, MBChB, MMed, MPH, § Jennifer S. Smith, PhD, MPH,\| A. Omu Anzala, MBChB, PhD, *q \\ Joshua Kimani, MBChB, MPH,*\# and Rupert Kaul, MD, PhD*+**
}

Background: The hallmark of HIV infection is progressive but variable rates of systemic and mucosal CD4 depletion, leading to immunodeficiency. The impact of early HIV infection on cervical $\mathrm{CD}^{+} \mathrm{T}$-cell populations in humans remains poorly described.

Methods: We analyzed cytobrush-derived immune cells by flow cytometry and cytokines in cervicovaginal lavage from participants in early HIV ( $<6$ months postinfection), chronic HIV, and HIVuninfected controls.

Results: CD4:CD8 ratios declined rapidly in both the cervix and the blood following HIV infection. In contrast, absolute cervical CD4 ${ }^{+} \mathrm{T}$-cell counts in early HIV were comparable to HIV-uninfected participants, declining only in chronic infection. Early HIV infection was associated with increases in RANTES and MIP3a in cervicovaginal fluids. Concurrently, slight increases in activated cells $\left(\mathrm{CD} 38^{+} \mathrm{HLA}-\mathrm{DR}^{+}\right)$and higher levels of CTLA4 expression on Tregs in the cervix were observed. Although study groups did not differ with respect to levels of CCR5, integrin B7, or CD69, the frequencies of Th17 cells (defined as $\mathrm{CCR}^{+} \mathrm{CCR} 10^{-}$) was reduced by $>10$-fold in early HIV infection and Th1 cells (defined as $\mathrm{CCR}^{-} \mathrm{CXCR}^{+}$) were reduced by $>2$-fold.

Received for publication February 15, 2014; accepted August 26, 2014. From the *Department of Medical Microbiology, University of Nairobi, Nairobi, Kenya; †Department of Medicine, University of Toronto, Toronto, Ontario, Canada; $\$$ Centre for the AIDS Program of Research in South Africa (CAPRISA), University of KwaZulu-Natal, Durban, South Africa; §Department of Obstetrics, Kenyatta National Hospital, Nairobi, Kenya; ||Department of Epidemiology, University of North Carolina, Chapel Hill, NC; |Kenya AIDS Vaccine Initiative, Nairobi, Kenya; \#Department of Medical Microbiology, University of Manitoba, Winnipeg, Manitoba, Canada; and **University Health Network, University of Toronto, Toronto, Ontario, Canada.

Supported by grants from the Canadian Institutes of Health Research (MOP89983 to R.K.); patient care activities and the purchase of antiretroviral drugs were funded by the President's Emergency Plan for AIDS Relief (PEPFAR) Salary support was provided by the Canadian Institutes of Health Research and the International Infectious Diseases and Global Health Training Program (L.R.M.) and the Ontario HIV Treatment Network (R.K.).

Presented in part at the 20th Conference on Retroviruses and Opportunistic Infections (CROI) conference, March 3-6, 2013, Atlanta, GA.

The authors have no conflicts of interest to disclose.

Supplemental digital content is available for this article. Direct URL citations appear in the printed text and are provided in the HTML and PDF versions of this article on the journal's Web site (www.jaids.com).

Correspondence to: Lyle R. McKinnon, PhD, Centre for the AIDS Program of Research in South Africa (CAPRISA), University of KwaZulu-Natal, 719 Umbilo Road, Congella, Durban, South Africa 4013 (e-mail: sijuisijali@ gmail.com).

Copyright (C) 2014 by Lippincott Williams \& Wilkins
Although $\mathrm{CCR}^{+} \mathrm{CCR}_{10}{ }^{-}$cells did not differ in HIV receptor expression, these cells produced higher levels of interferon gamma and interleukin 17.

Conclusions: These data support the model of initial $\mathrm{CD}^{+}{ }^{+} \mathrm{T}$-cell depletion followed by overall T-cell influx in response to infection and concomitant increases in immune activation, inflammation, and regulatory markers. These data are among the earliest characterization of the cellular milieu in the female genital tract following male-to-female HIV transmission.

Key Words: HIV, early infection, $\mathrm{CD}^{+} \mathrm{T}$ cells, inflammation, chemokine receptors

(J Acquir Immune Defic Syndr 2015;68:6-12)

\section{INTRODUCTION}

Although other immune cells can become HIV infected, most evidence suggests that $\mathrm{CD}^{+}{ }^{+} \mathrm{T}$ cells at mucosal surfaces are the primary cellular targets of $\mathrm{HIV}^{1-3}$; therefore, their relative frequencies at the time of exposure may function as a determinant of HIV transmission. ${ }^{4}$ Although the differential susceptibility of activated cells has been demonstrated, ${ }^{5}$ an understanding of the how different $\mathrm{T}$ helper subsets are targeted by HIV in vivo remains only partially defined. ${ }^{6}$

The immunological and functional heterogeneity of helper T-cell subsets continues to be realized. These functions are most often defined by combinations of cytokine production and chemokine receptor expression that link cellular function to location by selective homing mechanisms. ${ }^{7}$ In addition to Th1 and Th2 cells, many new subsets continue to be described. $\mathrm{CD}^{+} \mathrm{T}$ cells that secrete interleukin 17 (IL17) (Th17 cells) were depleted in animal models and in some studies of HIV-infected humans, particularly from the gut. ${ }^{8}$ The nature of this loss and immune dynamics during early HIV infection, in general, are thought to be important predictors of HIV disease progression rates.

$\mathrm{CD}^{+} \mathrm{T}$ cells are transiently and rapidly depleted from the gut mucosa following simian immunodeficiency virus (SIV) and HIV infections and do not readily recover in the absence of treatment. ${ }^{9}$ Although well established in the gut, the kinetics of this loss from other mucosal sites is less consistent. A number of groups have characterized $\mathrm{CD}^{+} \mathrm{T}$-cell loss from the female genital tract during acute SIV infection of non-human primates. Some studies suggest genital CD4 
numbers are relatively maintained during HIV infection. ${ }^{10,11}$ Others suggest that $\mathrm{CD} 4^{+} \mathrm{T}$ cells are reduced at the endocervix during chronic HIV infection, ${ }^{12-15}$ but the impact of early HIV infection on mucosal $\mathrm{CD} 4^{+} \mathrm{T}$-cell subsets have not been well described. Understanding these could have important implications for understanding how HIV infection impacts genital health. To address this, we characterized the $\mathrm{CD}^{+}{ }^{+} \mathrm{T}$ cells and immune milieu of the cervix in participants during the early phase of HIV infection and compared these parameters to chronic HIV and HIV-uninfected controls.

\section{METHODS}

\section{Study Cohort}

All participants were enrolled from female sex worker cohorts in Nairobi. All gave informed written consent to participate in this cross-sectional study, which was approved at Institutional Review Boards at collaborating universities. The study was divided into 2 parts. In part 1, T-cell populations of participants in the early phase of HIV infection were compared with HIV-uninfected and chronic HIV-infected antiretroviral therapy-naive participants. Based on these initial results, we expanded our flow cytometry panel to better understand the types of $\mathrm{T}$ cells that might be altered in early HIV. In this second part, additional early HIV-infected individuals were compared with additional HIV-infected (untreated) and HIVuninfected participants. A random convenience sample was selected for both parts based on the criteria established for study groups (described below), and sample sizes for each part are reported in their respective Results sections.

As a part of routine clinical care, participants received health education and HIV/sexually transmitted infection prevention and treatment as per national Kenyan guidelines. Early HIV infection was defined as those sampled less than 6 months since estimated time of HIV infection, calculated as the midway point between the last negative and first positive visit. All participants in the HIV-infected group had been HIV + for $>9$ months at the time of sampling and were not yet initiated on antiretroviral therapy. HIV-uninfected participants were selected on the basis of a negative HIV serological test. No participants were pregnant or menstruating at the time of sample collection.

Cervical mononuclear cells were isolated from study participants by a combined endocervical cytobrush and ectocervical spatula sample, as described. ${ }^{16}$ Cervicovaginal lavage (CVL) samples [3 $\mathrm{mL}$ of phosphate-buffered saline (PBS)] were also collected from the same visits. HIV testing was performed by rapid test (Determine; Inverness Medical, Waltham, MA) and confirmatory enzyme-linked immunosorbent assay (Vironostika; Biomerieux, Craponne, France). CD8 and CD4 counts in the blood were measured using Becton Dickinson Trucount reagents [Becton Dickinson (BD), Franklin Lakes, NJ], and sexually transmitted infection diagnostics were performed, including Chlamydia trachomatis (Roche Amplicor), Neisseria gonorrhoeae (Roche Amplicor), Trichomonas vaginalis (In-Pouch Kit; Biomed Diagnostics Inc., Singapore), rapid plasma reagin for syphilis (Diagnostics Worldwide), and bacterial vaginosis (Gram stain and Nugent scoring). Genital HIV viral load (VL) was measured on a subset of early infection participants using the Roche Amplicor test.

\section{Mucosal Sampling and Processing}

CVL samples were taken by applying $2 \mathrm{~mL}$ of sterile PBS over the ectocervix and collected using transfer pipette from the posterior fornix. Subsequently, one endocervical cytobrush followed by one ectocervical cell spatula and PBS mini-lavage was collected into $10 \mathrm{~mL}$ of PBS. Cytobrushes were placed into the cervical os, rotated 360 degrees, and placed into the tube. An Ayres spatula was gently run over the ectocervix, with a 2-mL lavage to collect cells from the posterior fornix. ${ }^{17}$ Specimens were combined in the same tube and transported to the laboratory on ice within 4 hours of collection. Cervical mononuclear cells were vortexed, filtered through a $100-\mu \mathrm{m}$ filter, washed once, and resuspended in PBS-1 before staining. Cells were cryopreserved in liquid nitrogen in media containing $10 \%$ dimethyl sulfoxide and $90 \%$ fetal bovine serum.

\section{Flow Cytometry for Cell Surface Phenotyping}

Cryopreserved cells from selected participants were thawed and washed in warm media containing RPMI 10\% fetal bovine serum, followed by further washing in PBS-1. Cells were then stained in 96-well V-bottom plates with a panel of surface antibodies (to avoid cell permeabilization in cervical samples) in various combinations. These included CD3-Alexa700, CD4ECD (Beckman Coulter), CD8-V450, CD69-PECy7, CCR5APCCy7, CXCR3-FITC, CD161-FITC, CCR10-PE (R\&D Systems), CTLA4-PE, HLA-DR-APC, CD39-APC, integrin ß7-PECy5, CCR6-PECy7, CD38-V450, and CD25-V450. All antibodies were from unless otherwise indicated. Cells were stained with pre-titrated amounts of antibodies and Live-Dead Aqua (Invitrogen) for 20 minutes at room temperature, washed, and fixed in $1 \%$ paraformaldehyde. Fixed samples were acquired on a BD LSRII configured for 10 colors. The entire cervical sample was acquired to estimate the total number of cells recovered. Data were analyzed using FlowJo v. 8.8.6 for Mac. Gates were set using fluorescence minus one controls.

\section{Stimulations}

We measured cytokine expression in various $\mathrm{CD}^{+} \mathrm{T}$ cell subsets, as defined by CCR6, CCR10, and CXCR3 expression. Peripheral blood mononuclear cells were stimulated with phorbol 12-myristate 13 -acetate $(1 \mathrm{ng} / \mathrm{mL})$ and ionomycin $(1 \mu \mathrm{g} / \mathrm{mL})$ for 6 hours at $37^{\circ} \mathrm{C}$, with Brefeldin A (BD; $1 \mu \mathrm{L}$ per $\mathrm{mL}$ ) added for the last 5 hours. Following stimulation, cells were washed and stained with monoclonals for surface markers, including CD3, CD4, CCR6, CXCR3, CCR10, and Live-dead for 30 minutes at $4^{\circ} \mathrm{C}$. Cells were then washed, permeabilized for 15 minutes using Perm/wash buffer (BD), and stained with intracellular cytokine monoclonal antibodies, including interferon gamma, IL-17a, and IL-22 for 30 minutes at $4^{\circ} \mathrm{C}$. Samples were fixed with $2 \%$ paraformaldehyde and acquired immediately on a BD Fortessa. At least 500,000 events within the lymphocyte gate were acquired per sample and background values were subtracted. Th17 cells were defined as those expressing CCR6 and not CCR10, whereas Th1 cells were those expressing CXCR3 but not CCR6, as described elsewhere. ${ }^{18-20}$ 


\section{Quantitation of Soluble Markers}

Soluble factors were quantified from CVL using the Meso Scale Discovery electrochemiluminescent enzyme-linked immunosorbent assay system and compared between participant groups. A panel of 14 markers was assessed (GM-CSF, IL-1a, IL-8, MCP1, MIG, MIP3a, RANTES, IL-10, IL-17, IL-1b, IL-6, IP10, MIP1b, and TNF-a). CVL was plated at $50 \mu \mathrm{L}$ per well and run in duplicate. A standard curve was used to determine the concentration (in picogram per milliliter). The lower limit of quantitation was determined as the dilution in which the coefficient of variation exceeded $30 \%$. Any sample above the range of the standard curve was repeated following dilution. Samples were run and analyzed by personnel who were blinded to study status.

\section{Statistical Analyses}

All cytokine data were $\log _{10}$ transformed to normalize distributions for parametric analyses. Flow cytometry data were analyzed using nonparametric tests. $P$ values $<0.05$ were considered statistically significant.

\section{RESULTS}

\section{Study Participants}

The first phase of the study compared cervical CD4 ${ }^{+} \mathrm{T}$-cell numbers and CD4:CD8 ratios between participants with early HIV-1 infection and controls, whereas the second phase compared the relative frequencies of particular $\mathrm{CD}^{+} \mathrm{T}$-cell subsets between groups. A random convenience sample was recruited for these consecutive phases on the basis of the study group definitions described in the Methods section. Selected demographic and clinical data for all study groups are shown in Table 1. The median estimated time from infection to sampling in the early group was 93 days (interquartile range, 70-125 days). Samples were only available to conduct cervical viral load analyses on 7 of 11 participants in early HIV infection. VL was detected in 4 of 7 , at a median of 1422 copies per milliliter, a detection frequency and level that is similar to that observed in separate HIV+ chronically infected cohorts. ${ }^{21}$

\section{Decreased CD4:CD8 Ratios Were Observed in the Cervix During Early HIV Infection}

We first compared the frequencies of $\mathrm{T}$ cells (part 1), expressed as a ratio of the proportions of $\mathrm{CD} 4^{+} / \mathrm{CD}^{+} \mathrm{CD} 3^{+}$ $\mathrm{T}$ cells, in the cervix and blood of all participants (Fig. 1A). This comparison included participants in early $\operatorname{HIV}(n=5)$, chronic HIV ( $\mathrm{n}=17)$, and HIV-uninfected controls $(\mathrm{n}=21)$. As expected, CD4:CD8 ratios were dramatically decreased in the blood and cervix of all HIV+ participants compared with matching compartments of HIV-uninfected controls (Fig. 1B, $P<0.001)$. A slightly lower CD4:CD8 ratio was observed in the cervix compared to matching blood samples of HIVuninfected participants, although this was not statistically significant $(P=0.19)$. In contrast, cervical CD4:CD8 ratios were significantly lower than that of blood for both HIV-infected groups (early, $P=0.028$; chronic, $P=0.0004$ ). These data suggest that naturally lower CD4:CD8 ratios are decreased even further by HIV infection, even as early as the first few months.
TABLE 1. Demographic and Clinical Characteristics of Study Participants

\begin{tabular}{lccc}
\hline Variable & $\begin{array}{c}\text { HIV+ Early } \\
(\mathbf{n}=\mathbf{1 1})\end{array}$ & $\begin{array}{c}\text { HIV+ Chronic } \\
(\mathbf{n}=\mathbf{2 6})\end{array}$ & $\begin{array}{c}\text { HIV } \\
\text { Uninfected } \\
(\mathbf{n}=\mathbf{1 3 2})^{*}\end{array}$ \\
\hline $\begin{array}{l}\text { Age, median (IQR), } \\
\text { yr }\end{array}$ & $32(28-34)$ & $34(30-40)$ & $31(27-37)$ \\
$\begin{array}{l}\text { Estimated days since } \\
\text { HIV infection } \\
\text { (median, IQR) }\end{array}$ & $93(70-125)$ & $826(261-2285)$ & $\mathrm{n} / \mathrm{a}$ \\
$\begin{array}{l}\text { CD4 count (median, } \\
\text { IQR) }\end{array}$ & $475(130-478)$ & $331(301-590)$ & \\
$\begin{array}{l}\text { STI at study visit } \\
\text { NG }\end{array}$ & $0 \%(0 / 11)$ & $12.0 \%(3 / 25)$ & $0.8 \%(1 / 122)$ \\
CT & $9.1 \%(1 / 11)$ & $4.0 \%(1 / 25)$ & $1.6 \%(2 / 122)$ \\
TV & $0 \%(0 / 11)$ & $4.0 \%(1 / 25)$ & $3.3 \%(4 / 122)$ \\
BV & & & \\
$\quad$ Intermediate & $18.1 \%(2 / 11)$ & $0 \%(0 / 13)$ & $9.5 \%(2 / 21)$ \\
$\quad$ BV & $18.1 \%(2 / 11)$ & $69.0 \%(9 / 13)$ & $52.3 \%(11 / 21)$ \\
RPR & $9.1 \%(1 / 11)$ & $0 \%(0 / 12)$ & $0 \%(0 / 21)$ \\
Contraception use & $45.5 \%(5 / 11)$ & $27.8 \%(5 / 18)$ & $39 \%(7 / 19)$ \\
(\% using & & & \\
hormonal) & & & \\
\hline
\end{tabular}

*Definition of study groups: (1) HIV uninfected by serologic testing at the time of the study, (2) HIV-infected participants who were recently diagnosed ("HIV+ Early"), (3) HIV-infected participants not in early infection and ART naive.

$\mathrm{BV}$, bacterial vaginosis; CT, Chlamydia trachomatis; IQR, interquartile range; n/a, not applicable for this study group; NG, Neisseria gonorrhoeae; RPR, rapid plasma reagin; STI, sexually transmitted infection; TV, Trichomonas vaginalis.

\section{Number of Cervical CD4 ${ }^{+}$T Cells Was Decreased in Chronic but not Early HIV Infection}

In addition to the relative ratio of T-cell subsets, we acquired the entire cytobrush sample from each participant in a blinded fashion, allowing us to also compare the overall number of $\mathrm{CD}^{+} \mathrm{T}$ cells between participant groups. For this comparison, we included data from parts 1 and 2 (described below), which included participants in early HIV $(n=11)$, chronic HIV $(n=26)$, and HIV-uninfected controls $(n=132)$. The numbers of cervical $\mathrm{CD}^{+} \mathrm{T}$ cells in early HIV infection were comparable to HIV-uninfected women (median 1524 vs. $1852, P=0.6$, Fig. 1C). This is in contrast to women with chronic HIV infection, who had a $0.5 \log _{10}$ decrease in $\mathrm{CD}^{+}$ cell number (median 351) compared with HIV-uninfected $(P<0.001)$ and early HIV-infected women $(P=0.003)$. These data suggest that although CD4:CD8 ratios decrease rapidly following infection, $\mathrm{CD}^{+} \mathrm{T}$-cell counts remain stable in the first few months of HIV infection.

\section{Frequencies of Chemokine Receptor-Defined Subsets Are Decreased in Early HIV Infection}

Although $\mathrm{CD}^{+}{ }^{+} \mathrm{T}$ cells were not decreased in number in early HIV infection, there could be changes in the frequencies of various CD4 subpopulations, defined by their surface marker expression. To this end, we extended our initial study by enrolling additional participants to compare the relative frequencies of $\mathrm{CD}^{+} \mathrm{T}$ cells expressing various combinations 
FIGURE 1. Reduced CD4:CD8 ratios but not frequencies in early HIV infection are accompanied by increased levels of genital tract chemokines. A, Representative flow cytometry plots for blood and cervical T-cell staining in the 3 participant groups. All plots were gated on live singlets and $\mathrm{CD}^{+}$cells. $\mathrm{B}, \mathrm{CD} 4: \mathrm{CD} 8$ ratios are compared in the peripheral blood ( $P$, closed squares) and the cervix ( $C$, open squares) in matched participants for each study group. $P$ values for the HIV - vs. HIV+ comparisons were all significant but not shown on the graph (see text for details). C, The numbers of cervical CD4 ${ }^{+} \mathrm{T}$ cells/cytobrush are compared between early, chronic, and uninfected participants.
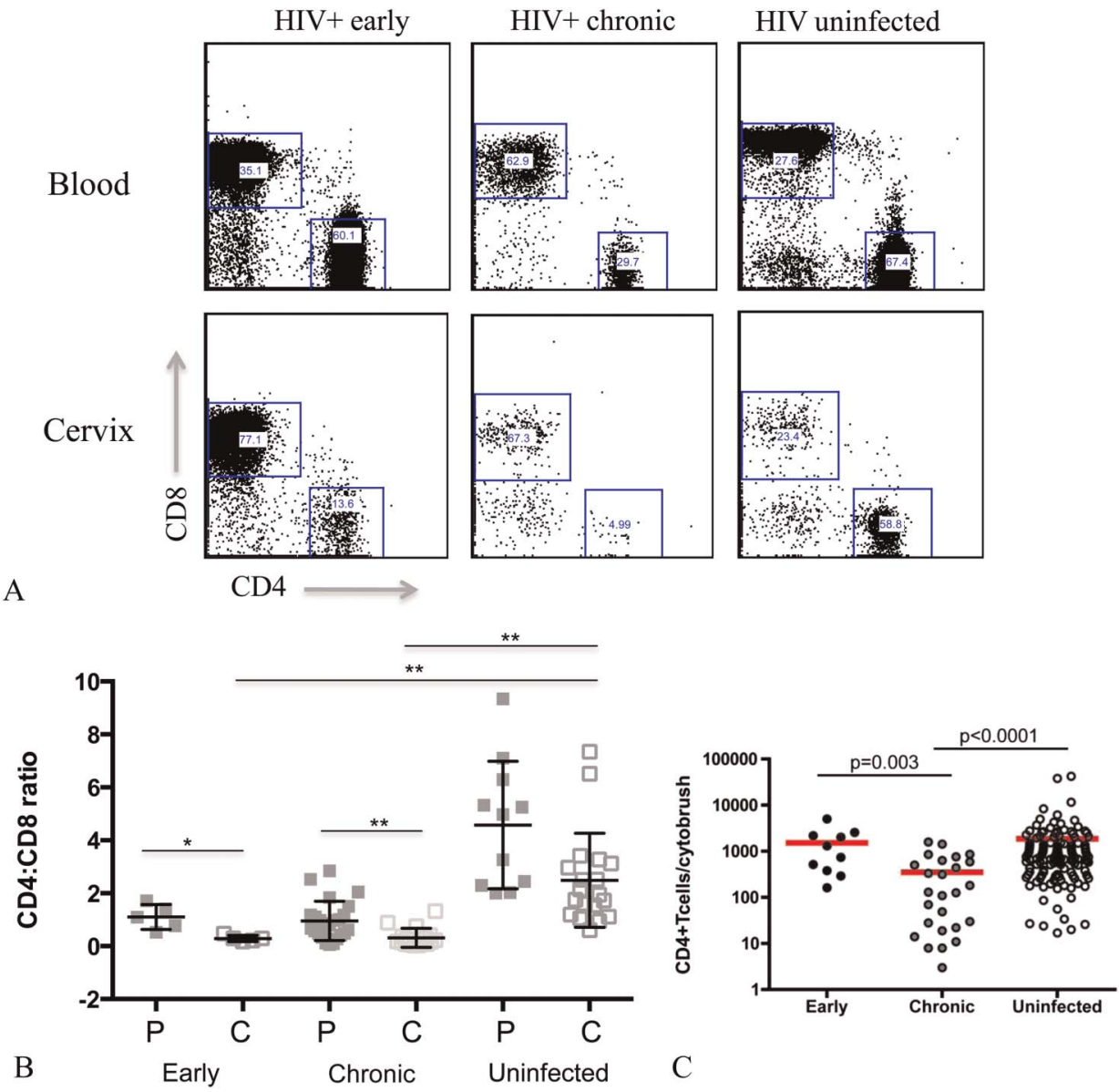

C of chemokine receptors, activation markers, and HIV coreceptors. This comparison included participants in early HIV $(\mathrm{n}=6)$, chronic HIV $(\mathrm{n}=9)$, and HIV-uninfected controls $(\mathrm{n}=113)$. Th17 cells, defined here as $\mathrm{CCR}^{+} \mathrm{CCR} 10^{-} \mathrm{CD} 4^{+}$ $\mathrm{T}$ cells, were depleted by 10 - to 15 -fold in early HIV infection compared with uninfected and chronically infected participants (median $1.6 \%$ vs $24.6 \%$ and $32.0 \%, P<0.001$ and 0.0004 ; Fig. 2A). A more modest 2-fold reduction in Th1 cell frequency (defined as $\mathrm{CCR}^{-}{ }^{-} \mathrm{CXCR}^{+}$) was observed in the same groups (median 8.9 vs. 16.9 and $16.7, P=0.026$ and 0.018 ). No changes in overall levels of CCR5, integrin beta7, or CD69 were observed, although a slight decrease in CD69 mean fluorescence intensity was observed in early HIV $(P=0.032$; see Figure S1, Supplemental Digital Content, http://links.lww.com/QAI/A583). These data suggest that in first months of HIV infection, certain cervical T-cell populations are decreased compared with HIV chronic and uninfected controls.

\section{Soluble Inflammatory Markers Are Increased in Cervicovaginal Fluid During Early HIV Infection}

Previous studies suggest that acute HIV infection is associated with genital tract inflammation. ${ }^{22}$ We next assessed levels of inflammatory cytokines in the genital tract from the participants in part 2 of the study using a multiplex panel of 14 cytokines. Ten of 14 markers were detected in $>90 \%$ of participants and analyzed as continuous variables. Early HIV was associated with significant increases for both RANTES and MIP3a, the ligands of CCR5 and CCR6, respectively (Fig. 2B). The median levels of RANTES were 17.6, 3.1, and $3.5 \mathrm{pg} / \mathrm{mL}$ in the early, chronic, and uninfected groups, respectively $(P<0.0001$ and $P=0.003$ for early vs. uninfected and early vs. chronic, respectively); corresponding values for MIP3a were 543.4, 146.4, and $134.3 \mathrm{pg} / \mathrm{mL}(P=$ 0.016 and 0.07). Slight increases in CXCR3 ligands IP10 and MIG were also observed, although these were not statistically significant $(P>0.1$, data not shown). This confirms that early HIV infection is associated with acute mucosal inflammation, which may have implications for the immune cell frequencies measured at this time.

\section{Expression of Regulatory and Activation Markers is Slightly Increased in Early HIV Infection}

We also compared frequencies of mucosal regulatory $\mathrm{T}$ cells between participant groups, using CD25, CD39, and CTLA-4 expression (Fig. 3). FoxP3 was omitted to avoid cell loss because of permeabilization. Although $\mathrm{CD} 25^{+} \mathrm{CD} 39^{+} \mathrm{CD} 4^{+}$ 

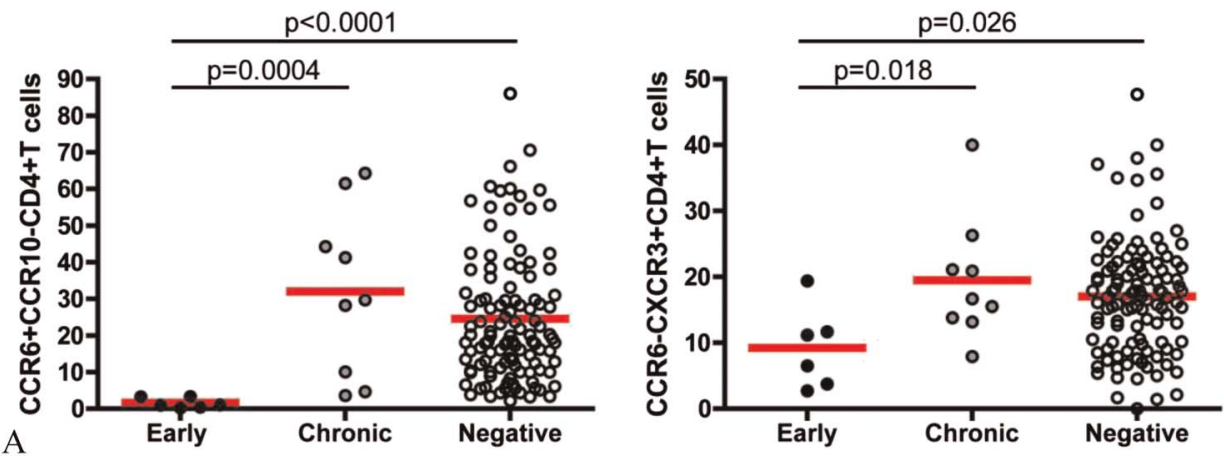

FIGURE 2. Depletion of $\mathrm{CCR}^{+} \mathrm{CCR} 10^{-} \mathrm{CD}^{+} \mathrm{T}$ cells during early HIV infection. A, Frequencies of $\mathrm{CCR}^{+} \mathrm{CCR} 10^{-} \mathrm{CD} 4^{+}$and $\mathrm{CCR}^{-}{ }^{-} \mathrm{CXCR} 3^{+} \mathrm{CD} 4^{+} \mathrm{T}$ cells in each study group. B, Concentrations of RANTES and MIP3a in each study group.
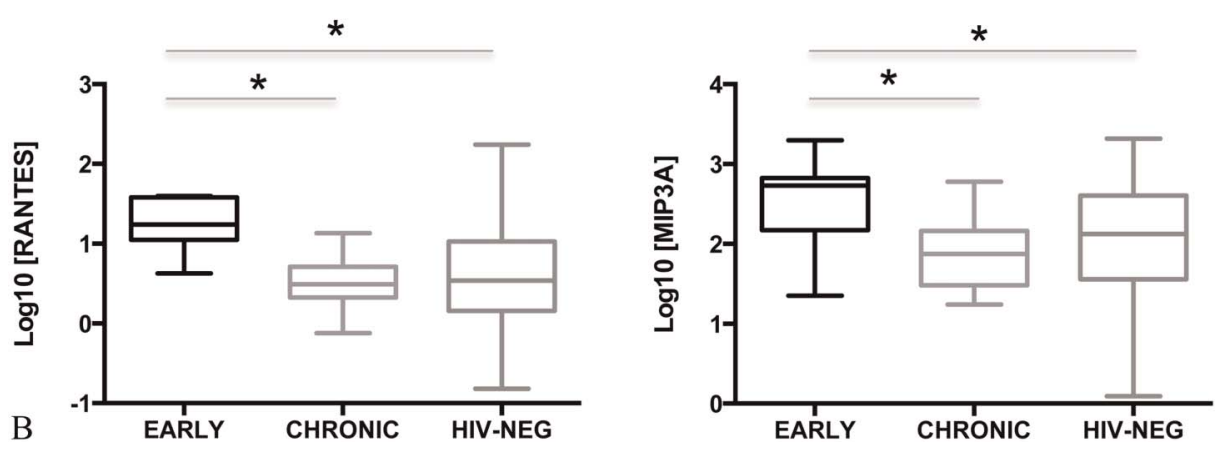

T-cell (Treg) frequencies did not differ between HIV early and uninfected participant groups (median $47.4 \%$ vs. $35.9 \%, P=$ 0.27 ), Tregs were increased in chronic HIV infection (median $54.4 \%)$ compared with the uninfected group $(P=0.0083)$. Tregs constitutively express CTLA-4, and CTLA-4 expression on $\mathrm{CD} 39^{+} \mathrm{CD} 25^{+}$Tregs was further increased in early HIV infection compared with either control group (early,
$96.2 \%$ vs. chronic, $89.2 \%, P=0.036$; and uninfected, $86.8 \%, P=0.002)$. In addition to Tregs, we also compared levels of chronic immune activation markers in early HIV infection at the cervix, based on CD38 and HLA-DR expression. In contrast to the early activation marker CD69, there was a trend to increased levels of $\mathrm{CD} 38^{+} \mathrm{HLA}-\mathrm{DR}^{+} \mathrm{CD} 4^{+}$ $\mathrm{T}$ cells in the early versus chronic and uninfected groups
FIGURE 3. Frequency of regulatory $T$ cells and CTLA4 expression in early HIV infection. CD25+CD39+ Tregs (left), CTLA4 ${ }^{+} \mathrm{CD}^{2} 5^{+} \mathrm{CD} 39^{+}$Tregs (middle), and CD38+HLA-DR (right) $\mathrm{CD}^{+} \mathrm{T}$ cells are compared between groups. Red bars indicate medians. $P$ values were calculated using the Mann-Whitney test.
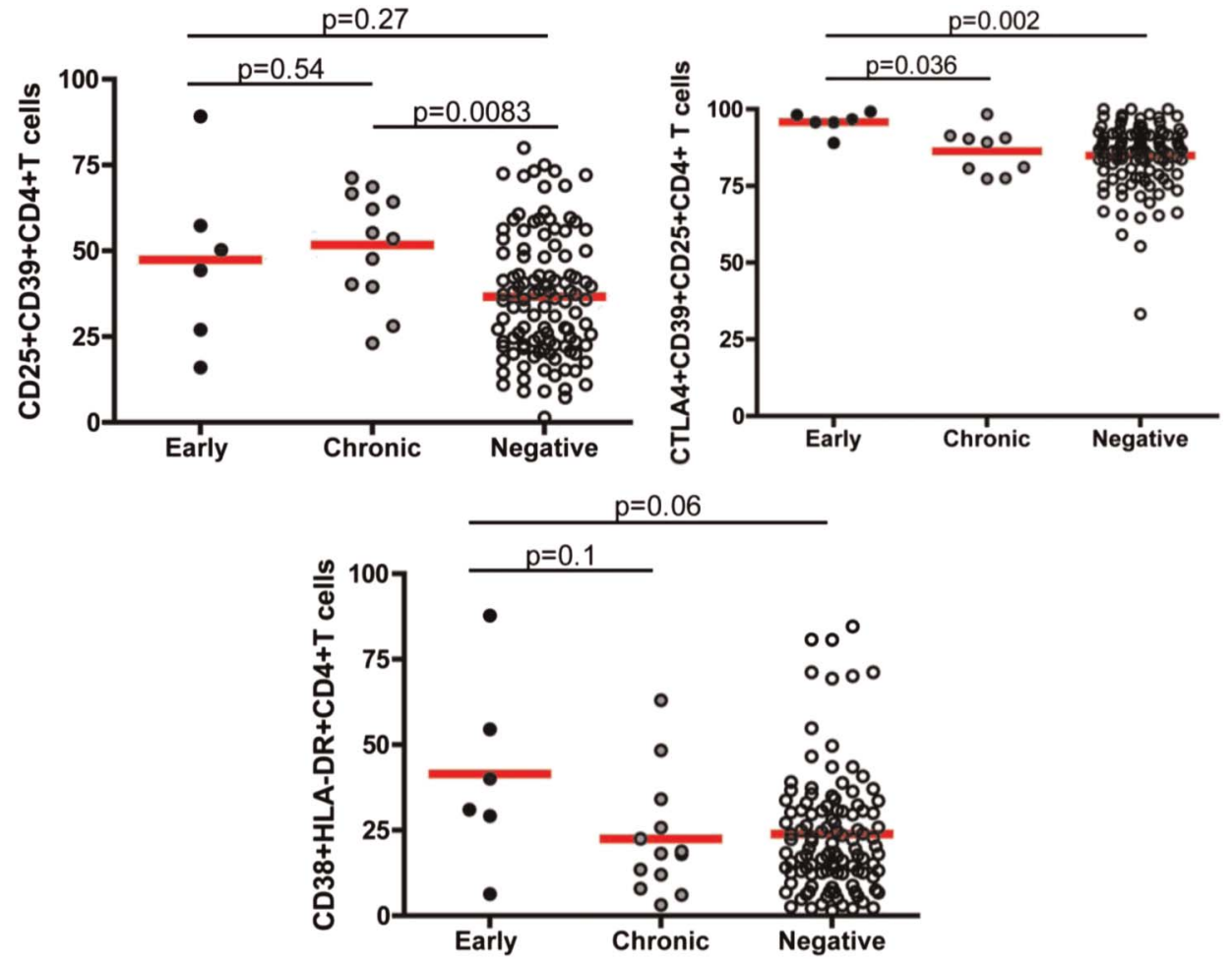

10 | www.jaids.com 
(35.6\% vs. $18.2 \%$ and $19.8 \%, P=0.1$ and 0.06 , respectively). These data suggest that early HIV is a dynamic time for cervical T-cell populations, with several subsets increasing or decreasing in their relative frequencies.

\section{HIV Receptor Expression and Cytokine Production by Depleted Cervical Subsets}

To determine potential reasons that could explain cervical Th17 depletion, we compared levels of HIV co-receptors and cytokine expression on various $\mathrm{T}$ helper subsets. There was no preferential CCR 5 expression on $\mathrm{CCR} 6^{+} \mathrm{CCR} 10^{-} \mathrm{CD} 4^{+} \mathrm{T}$ cells; in fact, it was the CCR $6^{+} \mathrm{CCR} 10^{+}$subset that had the highest CCR5 expression $(P<0.001$; Fig. 4A). Similar data were obtained for integrin beta7 (data not shown). In terms of cytokine production, technical limitations precluded reliable data on cytokine production from chemokine receptor subsets in cervical $\mathrm{T}$ cells. However, in the peripheral blood of 5 healthy donors, CCR6 ${ }^{+} \mathrm{CCR} 10^{-} \mathrm{CD} 4^{+} \mathrm{T}$ cells expressed significantly higher levels of both IL-17 and interferon gamma (analysis of variance, $P=0.014$; Fig. 4B). These data confirm that this chemokine receptor-defined subset is enriched for Th17 (and possibly Th1) cells, in line with previous observations. ${ }^{18-20}$

\section{DISCUSSION}

These data build on previous studies that reported $\mathrm{CD} 4^{+}$ T-cell depletion in the cervix in chronic HIV infection and acute CD4 depletion in non-human primate-SIV models, with
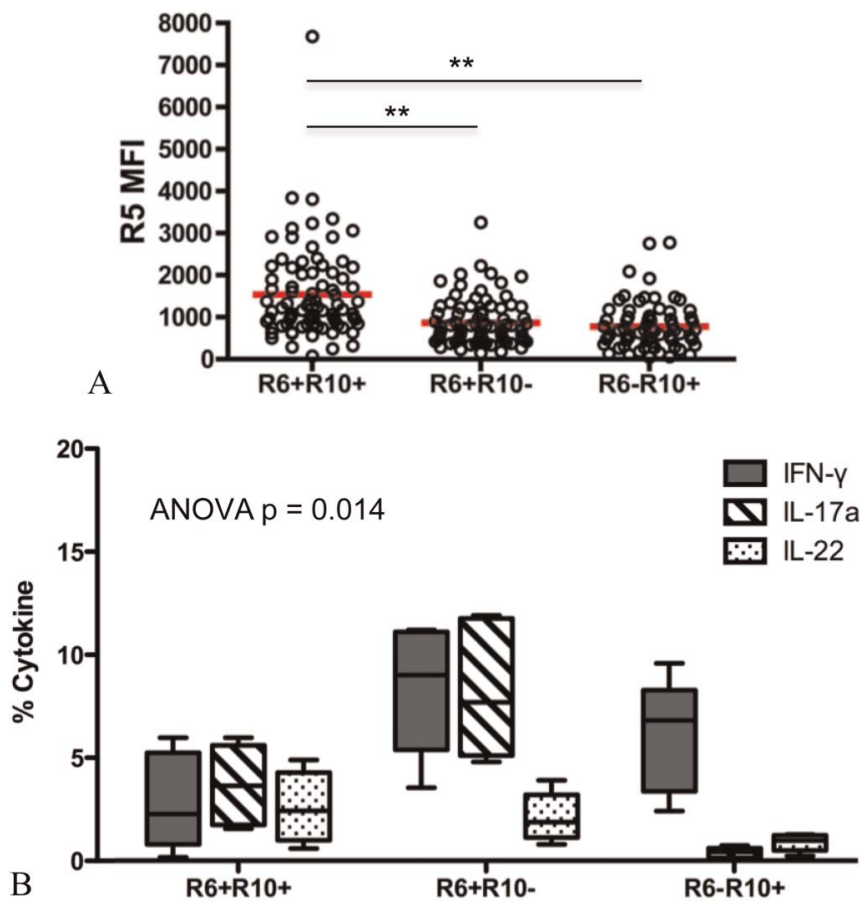

FIGURE 4. A, Mean fluorescence intensity (MFI) of CCR5 expression on 3 cervical CD4+ T-cell subsets defined by CCR6 and CCR10 expression. B, Cytokine expression (IFN- $\gamma$, IL-17a, and IL-22) in CCR6-defined and CCR10-defined subsets in peripheral blood $\mathrm{CD}^{+} \mathrm{T}$ cells. implications for the potential kinetics and immunological details of this depletion. Broadly, the number of cervical $\mathrm{CD}^{+} \mathrm{T}$ cells did not differ between early HIV and HIVuninfected participants, but the $\mathrm{CD} 4: \mathrm{CD} 8$ ratio declined rapidly following HIV infection (earlier than the blood). The effect of early HIV on the CD4:CD8 ratio but not overall CD4 number is likely explained by an influx of T cells in general - and particularly those expressing CD8 - during this phase of HIV infection. Mucosal inflammation is prominent during this early phase, and therefore, a combination between immune cell influx and loss is a logical response to infection. The finding of proportionally fewer mucosal CD4 cells, even in the absence of HIV infection, is physiologically consistent with $\mathrm{CD}^{+} \mathrm{T}$ cells having a higher tendency toward effector function and their emerging roles as tissue resident memory cells. ${ }^{7} \mathrm{HIV}$ infection seems to exacerbate this difference, and at a very early stage posttransmission, resulting in apparently stable cervical CD4 numbers that is likely a combination of CD4 depletion and general T-cell influx.

Our study is also the first to analyze cervical CD4 subsets in the context of early HIV and found that Th17 cells were almost completely depleted at this stage of infection. Several lines of evidence suggest that HIV might preferentially target Th17 cells, and we have shown that these cells are dramatically reduced from the cervix in chronic HIV infection. ${ }^{16}$ These data point to the importance of studying the effect of HIV on T-cell subsets not just overall numbers. In addition, Th17 cells are the most relevant with respect to defense against mucosal co-infections and their loss could possibly contribute to HIV shedding, inflammation, and onward HIV transmission during early HIV. It is important to note that in the current study we defined Th17 cells by chemokine receptor expression, as opposed to cytokine secretion in our previous study. It could be that the CCR $6^{+} \mathrm{CCR} 10^{-}$cells we measure in chronic HIV are not able to make IL-17 because of a functional impairment.

Questions around whether the cervical tissue represents an independent HIV reservoir or mere reflection of the systemic compartment have been raised. Phylogenetic differences between compartments support the argument for some degree of compartmentalization. ${ }^{23}$ Here we find increases in CCR5 and CCR6 ligands concomitant with depletion of a key $\mathrm{CCR}^{+} \mathrm{CD}^{+}{ }^{+} \mathrm{T}$-cell subset, raising the possibility that one effect of infection is mucosal recruitment of HIV target cells that supports further replication. However, there was no obvious increase in HIV shedding in early HIV participants for whom we had VL data. Resolution of this issue should have important implications for the impact of HIV infection on mucosal immunity at the site of exposure for women.

Limitations of our study include sampling a limited number of participants in early HIV infection, whether the timing was early enough to reflect events relevant to transmission, and low cell recovery from the cervix, precluding in-depth immunological characterization (including reliance on chemokine receptor-defined subsets). Although the latter is difficult to avoid in humans studied ex vivo, the others are important caveats. It is technically challenging to identify participants very early following transmission, but more studies along these lines should be attempted. Although the 
timing of the current sampling does not allow direct comparison to corresponding non-human primate studies, ${ }^{24}$ which can sample at the earliest time points a few days postinfection, this remains the earliest characterization in humans to date. Although our sample sizes were too small to detect small differences, the associations we present are statistically strong despite the small sample and may represent the most dramatic differences present at this important, dynamic stage of HIV pathogenesis.

In summary, our data suggest that early HIV infection has a profound impact on the frequency and balance of cervical $\mathrm{CD}^{+}{ }^{+} \mathrm{T}$-cell populations. A better understanding of the earliest events following HIV acquisition in humans could provide insight into HIV pathogenesis and the design of better prevention and treatment strategies.

\section{ACKNOWLEDGMENTS}

The authors would like to acknowledge the support of the Kenya AIDS Control Project and University of Toronto teams. In particular, the authors would like to thank Joshua Parmeres, Solomon Kamuti, Naomi Ireri, Jane Kamene, and Jane Njoki for clinical support, and Tabitha Wanjiru for help with data entry. The authors also thank the participants for volunteering for these studies.

\section{REFERENCES}

1. Hladik F, Sakchalathorn P, Ballweber L, et al. Initial events in establishing vaginal entry and infection by human immunodeficiency virus type- 1 . Immunity. 2007;26:257-270.

2. Haase AT. Perils at mucosal front lines for HIV and SIV and their hosts. Nat Rev Immunol. 2005;5:783-792.

3. Carias AM, McCoombe S, McRaven M, et al. Defining the interaction of HIV-1 with the mucosal barriers of the female reproductive tract. $J$ Virol. 2013;87:11388-11400.

4. McKinnon LR, Kaul R. Quality and quantity: mucosal CD4 ${ }^{+} \mathrm{T}$ cells and HIV susceptibility. Curr Opin HIV AIDS. 2012;7:195-202.

5. Zhang Z-Q, Wietgrefe SW, Li Q, et al. Roles of substrate availability and infection of resting and activated CD4+ T cells in transmission and acute simian immunodeficiency virus infection. Proc Natl Acad Sci USA. 2004; 101:5640-5645.

6. Gosselin A, Monteiro P, Chomont N, et al. Peripheral blood CCR4 +CCR6+ and CXCR3+CCR6+CD4+ T cells are highly permissive to HIV-1 infection. J Immunol. 2010;184:1604-1616.

7. Masopust D, Schenkel JM. The integration of T cell migration, differentiation and function. Nat Rev Immunol. 2013;13:309-320.
8. Brenchley JM, Douek DC. HIV infection and the gastrointestinal immune system. Mucosal Immunol. 2008;1:23-30.

9. Brenchley JM, Schacker TW, Ruff LE, et al. CD4 ${ }^{+} \mathrm{T}$ cell depletion during all stages of HIV disease occurs predominantly in the gastrointestinal tract. J Exp Med. 2004;200:749-759.

10. Hirbod T, Kimani J, Tjernlund A, et al. Stable CD4 expression and local immune activation in the ectocervical mucosa of HIV-infected women. J Immunol. 2013;191:3948-3954.

11. Prodger JL, Hirbod T, Gray R, et al. HIV infection in uncircumcised men is associated with altered CD8 T cell function but normal CD4 T cell numbers in the foreskin. J Infect Dis. 2013. doi: 10.1093/infdis/jit644.

12. Olaitan A, Johnson MA, MacLean A, et al. The distribution of immunocompetent cells in the genital tract of HIV-positive women. AIDS. 1996;10:759-764. Available at: http:/eutils.ncbi.nlm.nih.gov/entrez/eutils/ elink. fcgi? dbfrom $=$ pubmed $\&$ id $=8805867 \&$ retmode $=$ ref $\& \mathrm{cmd}=$ prlinks . Accessed February 12, 2014.

13. Quayle AJ, Kourtis AP, Cu-Uvin S, et al. T-lymphocyte profile and total and virus-specific immunoglobulin concentrations in the cervix of HIV1-infected women. J Acquir Immune Defic Syndr. 2007;44:292-298.

14. Nkwanyana NN, Gumbi PP, Roberts L, et al. Impact of human immunodeficiency virus 1 infection and inflammation on the composition and yield of cervical mononuclear cells in the female genital tract. Immunology. 2009;128(suppl 1):e746-e757.

15. Jaspan HB, Liebenberg L, Hanekom W, et al. Immune activation in the female genital tract during HIV infection predicts mucosal CD4 depletion and HIV shedding. J Infect Dis. 2011;204:1550-1556.

16. McKinnon LR, Nyanga B, Chege D, et al. Characterization of a human cervical $\mathrm{CD}^{+} \mathrm{T}$ cell subset coexpressing multiple markers of HIV susceptibility. J Immunol. 2011;187:6032-6042.

17. Iqbal SM, Ball TB, Kimani J, et al. Elevated T cell counts and RANTES expression in the genital mucosa of HIV-1-resistant Kenyan commercial sex workers. J Infect Dis. 2005;192:728-738.

18. Annunziato F, Cosmi L, Santarlasci V, et al. Phenotypic and functional features of human Th17 cells. J Exp Med. 2007;204:1849-1861.

19. Acosta-Rodriguez EV, Rivino L, Geginat J, et al. Surface phenotype and antigenic specificity of human interleukin 17-producing $\mathrm{T}$ helper memory cells. Nat Immunol. 2007;8:639-646.

20. Duhen T, Geiger R, Jarrossay D, et al. Production of interleukin 22 but not interleukin 17 by a subset of human skin-homing memory $\mathrm{T}$ cells. Nature. 2009. Available at: http://www.nature.com/ni/journal/v10/n8/ abs/ni.1767.html. Accessed February 12, 2014.

21. Rebbapragada A, Wachihi C, Pettengell C, et al. Negative mucosal synergy between herpes simplex type 2 and HIV in the female genital tract. AIDS. 2007;21:589-598.

22. Roberts L, Passmore J-AS, Mlisana K, et al. Genital tract inflammation during early HIV-1 infection predicts higher plasma viral load set point in women. J Infect Dis. 2012;205:194-203.

23. Kemal KS, Foley B, Burger H, et al. HIV-1 in genital tract and plasma of women: compartmentalization of viral sequences, coreceptor usage, and glycosylation. Proc Natl Acad Sci U S A. 2003;100:12972-12977.

24. Li Q, Estes JD, Schlievert PM, et al. Glycerol monolaurate prevents mucosal SIV transmission. Nature. 2009;458:1034-1038. 